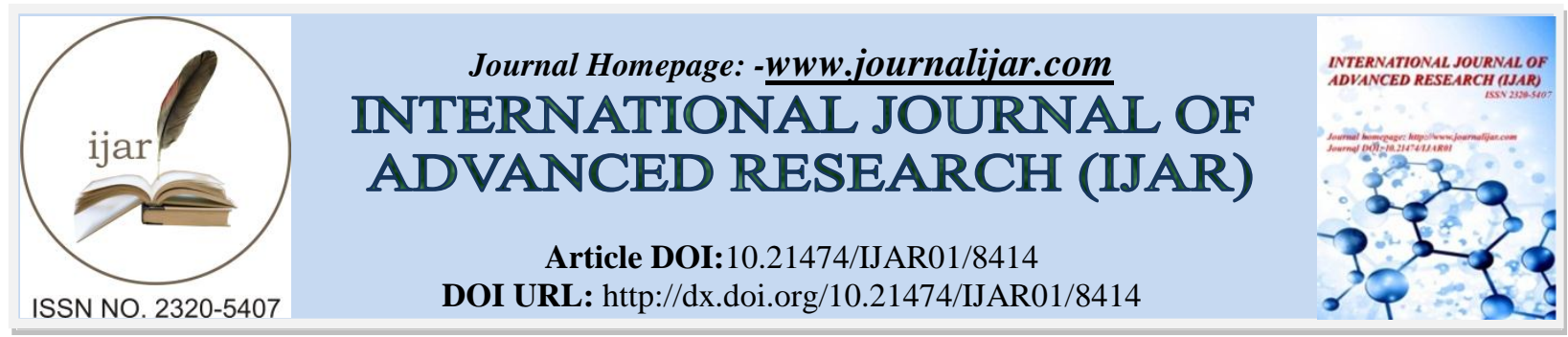

RESEARCH ARTICLE

\title{
POST-TRAUMATIC LONG DISTANCE COMPLETE DISTRACTION INJURY AT C2-C3 CERVICAL SPINE LEVEL:A CASE REPORT.
}

\author{
Mayank kumar.
}

Neurosurgery department, S.M.S, Jaipur.

\section{Manuscript Info}

\section{Manuscript History}

Received: 14 November 2018

Final Accepted: 16 December 2018

Published: January 2019

Key words:-

Complete long distance $\mathrm{C} 2 \quad-\mathrm{C} 3$ distraction, Cord transection, Post mortem findings

\begin{abstract}
Acute injury of spine and spinal cord are among the most common causes of death and disability resulting from trauma. Spinal cord injuries like, the most traumatic injuries, tend to occur in a young, predominantly male population. Motor vehicle accidents cause between $35 \%$ to $45 \%$ of traumatic injury with cervical segment being most commonly involved .Fall is the second most common cause of cervical spine injuries.

Judicial hangings are characterized by drops that are greater than the victim's height. In such drops, the head hyper-extends as the noose stops the victim. Classically, the result is bilateral fracture through the pedicles of $\mathrm{C} 2$ and the body of $\mathrm{C} 2$ is displaced anterior to the vertebral body of $\mathrm{C} 3$. The death is almost instantaneous in strangulation and a delayed death is very rare. Judicial hangings are uncommon worldwide. However, accidental hanging and strangulation injuries are becoming more prevalent in urban centres.

In paedriatric population, injuries are more common between occipital and $\mathrm{C} 2$ level. In adults $\mathrm{C} 3$ to $\mathrm{C} 7$ level are more involved due to more mobility at this level, withC2-C3 level injury being uncommon. Thus we hereby report a rare case of complete $\mathrm{C} 2-\mathrm{C} 3$ distraction about $3 \mathrm{~cm}$ long distance with complete spinal cord transection at lower cervical level with bilateral vertebral artery thrombosis but posterior circulation was intact. The patient survived for 9 days on ventilator support.
\end{abstract}

Copy Right, IJAR, 2017,. All rights reserved.

\section{Introduction:-}

Traumatic injuries of the upper cervical spine are often encountered, and may be associated to severe neurological outcome .Most common cause of traumatic cervical spine injury is road traffic accidents followed by high energy fall ${ }^{[5]}$. Anterior dislocation is most common at C5- C6 level due high mobility of this segment. In upper cervical spine it is more common at occipito-atlantal level and at C1-C2 level and in lower part ,C3 to C7 dislocation is common with $\mathrm{C} 2-\mathrm{C} 3$ being rare ${ }^{[9]}$ Here is a case of $\mathrm{C} 2-\mathrm{C} 3$ complete cervical spine distraction with complete cord transaction due to strangulation and traction injury.

\section{Case-Report:-}

A 25 years old female with alleged history of cloth (sari) stuck in a heavy machine at her work place and cloth got entangled around her neck. She fell on the ground, strangulated by the cloth, presented in state of unconsciousness and quadriplegia to a private hospital. There she was intubated and later transferred to our emergency department.

Corresponding Author:- Mayank kumar.

Address:-Neurosurgery department, S.M.S, Jaipur. 
At the emergency department she was evaluated and philadalphia collar was put around the neck. Her Glassgow Coma Scale (GCS) was 3/15. She was on ambu support as there was no spontaneous respiration. Herpupil was non reacting bilaterally and pulse was weak and thready with low blood- pressure. She was shifted on vasopressor support and her radiological work up was done. After which she was shifted to ICU.|CT of cervical spine revealed complete separation of $\mathrm{C} 2$ and $\mathrm{C} 3$ with displacement in both antero-posterior and vertical direction.

Noncontrast CT brain was having no gross abnormality. CT angiography of neck vessels was done which revealed non-visualisation of bilateral vertebral artery with appearance of distal vertebral artery at foramen -magnum. Circle of willis was also well seen along with posterior circulation .CT Venography was normal and was showing flow upto bilateral sigmoid sinus.

The patient's condition improved over the next 2 day. She has got spontaneous eye opening with bilateral pupil $3 \mathrm{~mm}$ reacting. But she was not obeying verbal command. She was not having spontaneous respiration and she was still on ventilator and vasopressor support .The patient survived for 9 days but latter expired due to cardiorespiratory arrest.

Her postmortem was done on same day. Post-mortem examination of the patient showed ligature mark with bruise at anterior and posterior part of neck at thyroid cartilage level. It also showed hematoma in subcutaneous and muscle plane in cervical region. On further examination, it showed separation of both facet joint and complete bony separation at C2- C3 level. Prevertebral hematoma was also noted. Separation was in vertical plane for $3 \mathrm{~cm}$ distance between $\mathrm{C} 2$ and $\mathrm{C} 3$ facet with cervical cord seen at this level but found to be transected at lower cervical level at C7-T1 level. On further examination vertebral artery was found transected at C3 level on one side while thrombosed with dark reddish blood on the other side. Transected cord margins were also contused.
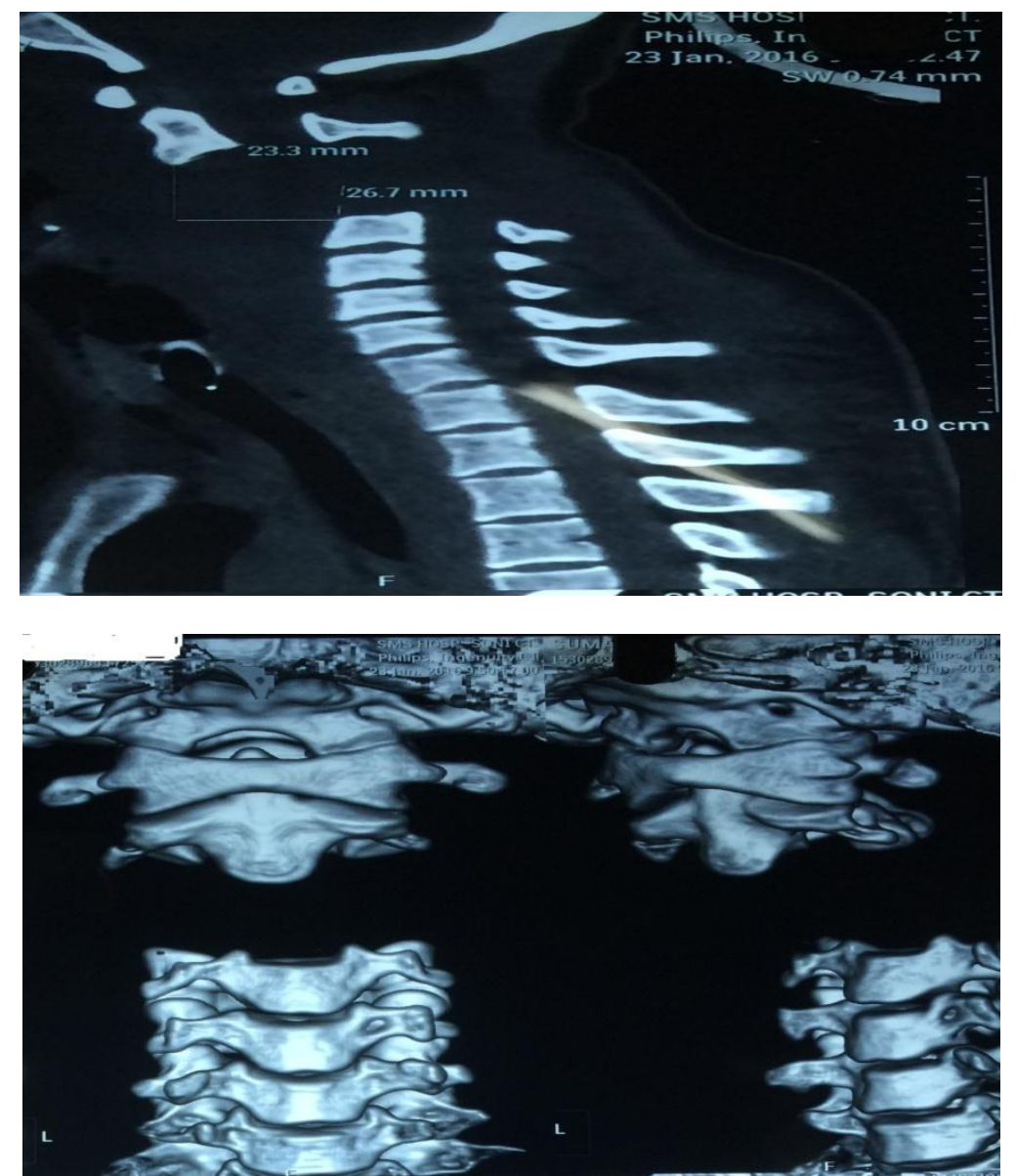

Figure 1 (B):-CT Cervical Spine 3-D reconstruction showing the complete distraction of C2-C3 with separation at all joints. 


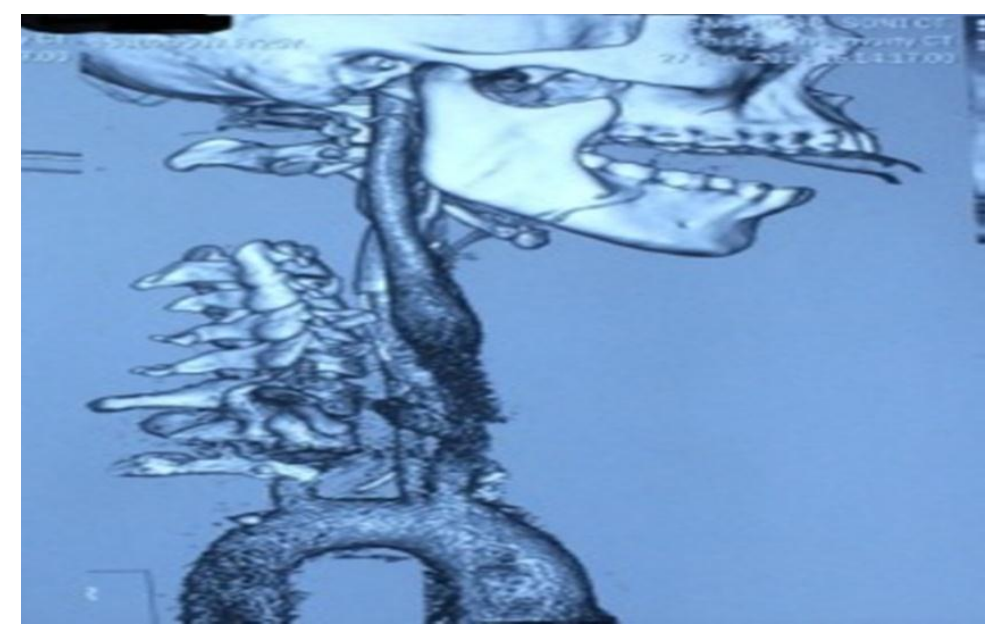

Figure 1 (C):-CT angiography of neck vessels with 3-D reconstruction showing non-visualisation of proximal vertebral artery bilaterally.

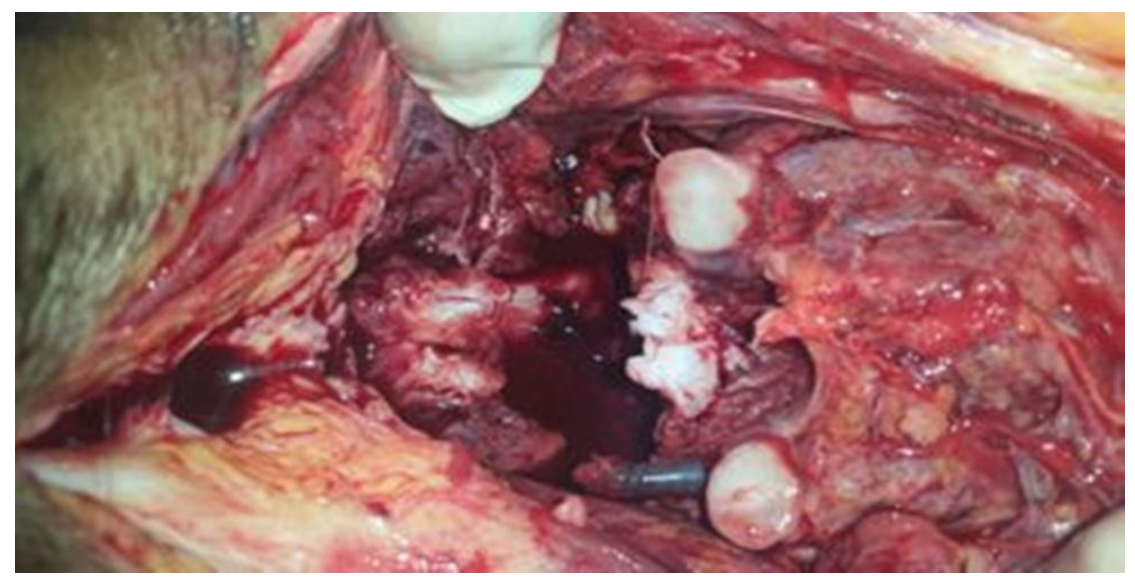

Figure 1(D):-showing blood flow upto distal vertebral artery with complete circle of willis and posterior circulation.

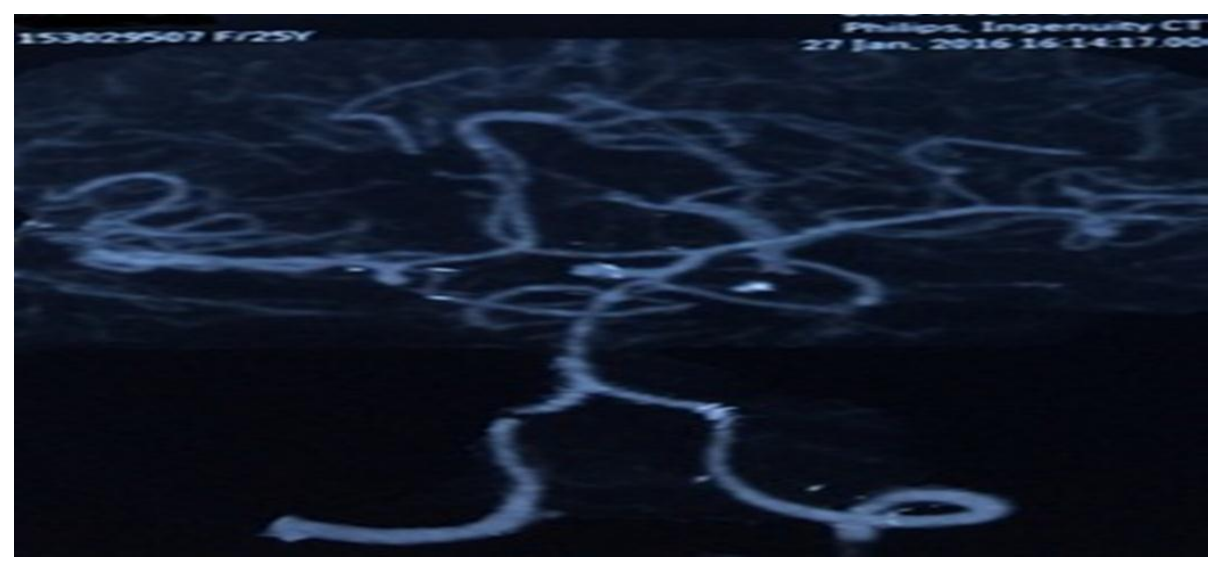

Figure 2 (A):-Post mortem findings showing avulsion at C2- C3 level at both facet joints with vertical displacement. Both vertebral artery are seen transected at C2- $\mathrm{C} 3$ level with reddish black blood in situ. 


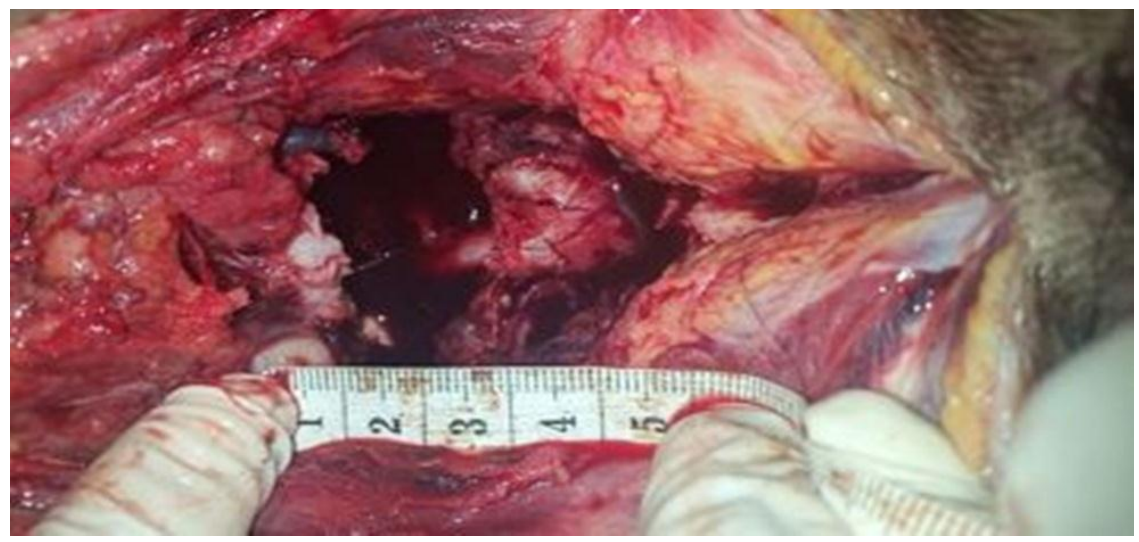

Figure 2(B):-Showing the distance between the $\mathrm{C} 2$ and $\mathrm{C} 3$ facets at post mortem which is approximately $3 \mathrm{~cm}$.

\section{Discussion:-}

Injury of the cervical spine is a potentially fatal and debilitating incident due to the risk of damage of the cervical spinal cord .Younis Kamal et al, in their literature, concluded that, falling used to be the most common mode of injury but now road traffic accidents are the commonest cause of such spinal injuries ${ }^{[1]}$. It is due to many fold increase in the vehicles on the congested roads and more hilly regions lead to more accidents.

The highest number of complete motor and sensory neurological deficits was found in cervical spine fractures (19.7\%).In a study by Younis Kamal et al, Upper cervical spine injury was $27.2 \%$ of the total cervical spine injuries and $14.15 \%$ of the total spine injury patients ${ }^{[1]}$.

It is interesting to note that our patient had no signs of posterior fossa infarction despite the fact that one of the vertebral artery was disrupted at C2-C3 level while another was totally thrombosed. Theofilos G. Machinis et al , also reported a case of $\mathrm{C} 2-\mathrm{C} 3$ dislocation with vertebral artery disruption at c2-c3 level with intact posterior fossa blood supply. He assumed that this is because of the presence of fetal circulation in his patient providing back flow to the basilar artery thus maintaining adequate perfusion of the posterior fossa ${ }^{[2]}$. This was also demonstrated in the CT angiography of our patient. According to Philip J. Torina et al, in his study of incidence of vertebral artery thrombosis in cervical spine injury, most frequent related injury associated with vertebral injury included spine fracture/dislocation (71\%), followed by chest and extremity injury $(45 \%)^{[3]}$.

In our case cervical cord was not injured at the level of distraction while it was completely transected at cervicodorsal junction.

It is recognized that fracture and dislocation of the cervical vertebra are seen in judicial hangings or hangings associated with long drop, it is not reported in ligature strangulation ${ }^{[5]}$. Bhullar et al, Agrawal et al and Gupta et al also reported a few cases of accidental ligature strangulation due to entanglement of the chunni (cloth) while moving in a vehicle like a rickshaw, motorcycle and bicycle. Thus, all reported cases of accidental strangulation involved vehicle and chunni /scarf; all occurred on the road and the victims died immediately due to asphyxiation but without cervical spine injury except case report of Gupta et al. in which there was a dislocation between the 2nd and 3rd cervical vertebrae.

Hence, till date, no literature is found with such long distance complete distraction in a living subject.

\section{Conclusion:-}

In conclusion, we are reporting a rare case of complete long distance $\mathrm{C} 2-\mathrm{C} 3$ cervical spine distraction with vertebral artery disruption and transaction of cord at cervico-dorsal junction. Despite such a severe inury the patient survived for 9 days. 


\section{Acknowledgement:-}

There is no source of any financial support.

\section{References:-}

1. Younis Kamal ,' Hayat Ahmad Khan, Naseemul Gani, Anil Gupta, Dara Singh, and Snobar Gul.A Study to Analyses Pattern and Treatment of Upper Cervical Spine Injuries Experience From Developing World.Trauma Mon. 2015 Aug; e19174.Published online . doi: 10.5812/traumamon.19174.

2. Theofilos G. Machinis, Kostas N. Fountas, E. Z. Kapsalaki, I. Kapsalakis, and A. A. Grigorian.A rare case of complete C2-C3 dislocation with mild neurological symptoms. Eur Spine J. 2006 ; 15(Suppl 5): 585589.Published online 2006 Jan 21. doi: 10.1007/s00586-005-0019-2

3. Philip J. Torina et al . Incidence of Vertebral Artery Thrombosis in Cervical Spine Trauma: Correlation with Severity of Spinal Cord Injury AJNR Am J Neuroradiol;2005 26:2645-51

4. D.S. Bhullar, O.P. Aggarwal.A rare case of accidental strangulation - a case study.Jn Forensic Med Toxic, 14 (2) (1997), p. 26

5. Leucht $\mathrm{P}^{1}$, Fischer $\mathrm{K}$, Muhr G, Mueller EJ.Epidemiology of traumatic spine fractures . Injury. 2009 Feb;40(2):166-72. doi: 10.1016/j.injury.2008.06.040. Epub 2009 Feb 23

6. Mills, MD, William $\quad$ Ernoehazy, Jr, MD, FACEP; Chief $\quad$ Editor: Trevor $\quad$ John $\quad$ MPH .emedicine.medscape.com/article/826704-overview,Jan 19, 2016

7. Nilesh Keshav Tumram ${ }^{1}$,Vipul Namdeorao Ambade. Fractured cervical vertebra in accidental strangulation by chunni. Egyptian Journal of Forensic Sciences Volume 6, Issue 1, Pages 1-28 (March 2016)

8. Dennis G. Vollmer,Marc E Eichler,Arthur L. Jenkins-3.Assessment of the cervical spine after trauma.In: Richard Winn,editor.Youmans neurological surgery, $6^{\text {th }}$ ed.Philadelphia:Elsevier Saunders;2011.p.3166-67. 